\title{
Who "Wins"? Determining the Party of the Prime Minister
}

\author{
Garrett Glasgow University of California, Santa Barbara \\ Matt Golder Pennsylvania State University \\ Sona N. Golder Pennsylvania State University
}

\begin{abstract}
The prime ministership is the preeminent political post in parliamentary democracies. Yet few studies examine PM party choice, perhaps under the assumption that the choice is a simple function of party size. In this article, we argue that key strategic actors and the context in which government negotiations take place can play a critical role in PM party choice. We test our hypotheses using a mixed logit with random coefficients on an original data set comprising PM selection opportunities in 28 European countries. Our methodological approach allows us to incorporate qualitative concerns about heterogeneity and causal complexity into our analysis. Contrary to conventional wisdom, we find that the largest party is often disadvantaged when it comes to PM party choice, that some presidents play an influential role in choosing the PM, and that the value of being the incumbent depends on one's performance in office and how the previous government ended.
\end{abstract}

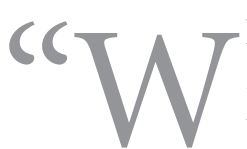

ho won?" is probably the first and most important question asked after an election in parliamentary democracies. The answer to this question is obvious when a single party controls a legislative majority and can choose to form a government on its own. However, it is not so obvious when, as is the norm in parliamentary democracies, no such party exists. In these situations, "who won" typically refers to the party that secures the prime ministership. Although which parties get into government obviously matters a great deal for voters and politicians alike, who gets to control the prime ministership is of particular import because the PM party tends to be privileged when it comes to making policy, setting the agenda, and controlling office benefits (Laver and Schofield 1990). Indeed, " $[t]$ he prime ministership ... is ... recognized in all countries and by all parties as the pre-eminent post" (Warwick and Druckman 2006, 640).
Given the importance of the prime ministerial position, it is somewhat surprising that scholars have paid so little attention to the factors influencing the choice of PM party. Although the government formation literature is quite extensive, most existing studies focus on the party composition of the government as a whole rather than on the allocation of specific portfolios such as the prime ministership. Indeed, we know of only five published articles addressing the choice of PM party (Bäck and Dumont 2008; Isaksson 2005; Kang 2009; Mattila and Raunio 2004; Warwick 1996). One potential explanation for this has to do with the widespread belief, promoted by the media and conventional scholarly wisdom, that the choice of PM party is a simple function of party size. As we demonstrate, though, things are much more complicated than this.

By emphasizing party-specific characteristics relating to things like legislative size, formal models of government

Garrett Glasgow is Associate Professor at the University of California, Santa Barbara, Department of Political Science, 3719 Ellison Hall, Santa Barbara, CA 93106 (glasgow@polsci.ucsb.edu). Matt Golder is Associate Professor at Pennsylvania State University, Department of Political Science, 306 Pond Laboratory, University Park, 16802 (mgolder@psu.edu). Sona N. Golder is Associate Professor at Pennsylvania State University, Department of Political Science, 305 Pond Laboratory, University Park, PA 16802 (sgolder@psu.edu).

We would like to thank Nathaniel Beck, Torbjörn Bergman, Patrick Dumont, Brad Gomez, Shin-Goo Kang, Michael Laver, G. Bingham Powell, Christopher Reenock, David Siegel, Greg Wawro, and four anonymous reviewers for helpful comments on this article. We also thank audiences at the 2010 Summer Political Methodology Meeting, Pennsylvania State University, Purdue University, and Texas A\&M University. The data and computer code to replicate the results and figures in this analysis, along with the online appendices that we refer to, are publicly available on the authors' homepages: http://www.polsci.ucsb.edu/faculty/glasgow/, http://homepages.nyu.edu/ mrg217/, and http://homepages.nyu.edu/ sln202/. All statistical models were estimated using code in either R or Stata.

American Journal of Political Science, Vol. 00, No. 0, xxx 2011, Pp. 1-18 
formation often overlook the process by which governments form and the key strategic actors who get to shape this process. Two such actors are the incumbent PM and the head of state. In this article, we argue that both of these actors can play a significant role in the choice of PM party, but that much depends on the dynamic and institutional context in which government negotiations take place. Although incumbency has traditionally been viewed as an advantage when it comes to government formation, recent work on the partisan composition of governments as a whole indicates that the existence of an incumbency advantage is context dependent (Martin and Stevenson 2010). Applying the same logic to the choice of PM party, we find that incumbent PM parties are more likely to be returned to power when they, but not necessarily their coalition partners, are electorally rewarded for their performance in office and when their governments end without public conflict.

On the whole, scholars pay relatively little theoretical attention to the role played by heads of state in the government formation process. One reason for this is that heads of state have traditionally been viewed as "senior statesmen," above the cut and thrust of everyday politics. Recently, though, this view has been challenged by an emerging literature documenting the political activism of presidents in nonpresidential democracies. In the government formation context, this has resulted in a growing number of studies examining presidential influence on the proportion of nonpartisan ministers in a cabinet (Amorim Neto and Strøm 2006; Schleiter and MorganJones 2009b; Tavits 2009). We expand this literature by arguing that there are many situations in which presidents have both the desire and ability to influence the partisan choice of PM party. Specifically, we claim that indirectly elected presidents have an incentive to help their own parties gain the prime ministership but that their ability to do this effectively depends on whether there is an investiture vote or not. Our empirical analysis bears this out.

We test our hypotheses with new data that we collected on governments in 11 Eastern European countries from 1990 to 2008, as well as data covering governments in 17 Western European countries from 1945 to 1998 (Strøm, Müller, and Bergman 2008). To date, there have been no quantitative empirical studies of PM party choice in Eastern Europe. Our data set is useful in that it allows us to examine whether the "general" theories of government formation that have typically been built with Western Europe in mind travel to other regions of the world. Eastern Europe offers a particularly fruitful place in which to evaluate cross-national theories of government formation because it shares a common set of parliamentary institutions with Western Europe but differs enormously in terms of its social, economic, cultural, and political context. For example, Eastern Europe has only limited experience with democracy, it continues to be influenced by its communist legacy, and it has had to manage a transition from a centrally planned economy to a capitalist one. Although country experts frequently criticize general models of government formation for failing to incorporate such noninstitutional contextual factors, our analysis suggests that such criticisms may be overstated. In general, we find only minor differences in the determinants of PM party choice across Western and Eastern Europe.

To test our hypotheses, we adopt a new empirical strategy - a random coefficient mixed logit model — that treats the PM party selection opportunity as the unit of analysis and allows the model coefficients to vary for unobserved or unmeasured contextual reasons (Glasgow 2001; McFadden and Train 2000; Train 1998). Qualitative researchers regularly criticize large- $N$ quantitative studies for ignoring differences in the social, political, and historical contexts of the cases they study in favor of treating all cases as homogeneous units, with the only interesting variation across cases captured by the observed variables. Indeed, it is well established that contextual factors, such as personality clashes and ad hoc critical events, can play a key role in the government formation process. Our random coefficient framework takes these concerns seriously by striking a balance between assuming that the only meaningful variation between PM selection opportunities is captured by our independent variables and assuming that each case is so unique that it cannot be meaningfully compared to others. Our application demonstrates that such an approach can help quantitative researchers address the heterogeneity and causal complexity that underlies almost all comparative politics research (Beck and Katz 2007; Western 1998).

\section{Theory and Hypotheses}

In this section, we outline our theoretical argument linking (1) party-specific characteristics, (2) the role of key strategic actors, and (3) the bargaining context to the choice of PM party.

\section{Party-Specific Characteristics}

Existing theoretical accounts of government formation focus almost exclusively on party-specific characteristics related to legislative size and ideology to explain PM party choice. For example, formal models that build on a Baron-Ferejohn (1989) sequential bargaining 
framework emphasize the importance of party size. This is because these models generally assume that formateurs are either chosen in order of party size starting with the largest or probabilistically where the probabilities are determined by party size. Significantly, the standard closedrule Baron-Ferejohn model predicts that the first formateur will successfully exploit her proposal power such that governments form immediately. A consequence is that the assumptions about formateur choice feed directly into the choice of PM party. ${ }^{1}$ In effect, formal models tend to predict that either the largest party or larger parties more generally have a higher probability of becoming the PM party.

- Largest Party Hypothesis: The largest party is more likely to be chosen as the PM party than other parties.

- Party Size Hypothesis: A party is more likely to be chosen as the PM party the larger its seatshare.

An obvious empirical question is whether there is a bonus for being the largest party above and beyond simply being a large party. Informal accounts of government formation often suggest that there is. Following legislative elections, for example, the media frequently refer to the largest party as the "winner" and assume that it will become the PM party. Similarly, the largest party regularly claims to have received a popular mandate and that it should therefore control the prime ministership. Our upcoming analysis throws light on whether there is, in fact, a largest party bonus.

Some models of government formation suggest that the ideological location of the legislative parties also matters for PM party choice. For example, spatial bargaining models that assume a single policy dimension indicate that the party controlling the median legislator is a dictator when it comes to policy. Significantly, this is true irrespective of the median party's actual legislative size (Laver and Schofield 1990, 111). Given its pivotal position in the policy space, these spatial models suggest that the median party has a higher likelihood of becoming the PM party.

- Median Ideological Party Hypothesis: A party is more likely to be chosen as the PM party if it is the median ideological party.

\footnotetext{
${ }^{1}$ Technically, formal bargaining models only assume that the formateur's party will be in the government. However, the general presumption in these models is that the formateur will be able to use her proposal power to not only be in the cabinet, but also obtain the prime ministership. This presumption is borne out in the real world where data on 14 countries in the postwar period indicate that only once has the PM position been obtained by a nonformateur party (Snyder, Ting, and Ansolabehere 2005).
}

This argument rests on the assumption that the relevant policy space is one-dimensional. While considerable research suggests that this assumption is reasonable in Western Europe, it is less clear that a single issue dimension accurately captures the policy space in Eastern Europe (Benoit and Laver 2006). A consequence is that we may find significant differences in the importance of the median ideological party across Western and Eastern Europe.

\section{Key Strategic Actors}

Two key strategic actors-the incumbent PM and the head of state-enjoy a privileged position in the government formation process (Strøm, Budge, and Laver 1994). The incumbent PM is important for at least two reasons. First, the incumbent PM is often chosen as the first formateur (Bäck and Dumont 2008) and can use her proposal powers to shape the government formation process to her advantage. Second, the government termination literature highlights the fact that the incumbent $\mathrm{PM}$ has the ability to strategically end governments at times when she expects her bargaining power, and hence her probability of being reselected as PM, to be high (Lupia and Strøm 1995; Schleiter and Morgan-Jones 2009a). For both of these reasons, we expect the incumbent PM party to have a greater chance of winning the prime ministership than other parties.

- Incumbent Prime Minister Hypothesis: The party of the incumbent PM is more likely to be chosen as the PM party than other parties.

In nonpresidential democracies, the head of state is either a monarch or a president. Given that monarchs are not explicitly affiliated with a particular political party and that they are supposed to fulfill only a symbolic role, we do not expect them to systematically affect the choice of PM party. As a result, we focus our attention on presidential heads of state. The fact that the presidency in nonpresidential democracies has traditionally been viewed as a ceremonial position of little political import has meant that scholars have paid relatively little attention to presidential heads of state. Although this has recently begun to change (Schleiter and Morgan-Jones 2009a; Tavits 2009), we know of only one study that explicitly looks at whether presidents influence the choice of PM party (Kang 2009).

Presidential heads of state are usually drawn from the ranks of career politicians, and we believe that it is probably unreasonable to think that they would relinquish their partisan convictions upon becoming president. Moreover, it is important to remember that the 
president officially appoints the formateur in many countries, and there are times when she might have some latitude to use this power to influence the choice of PM party (Protsyk 2005). Under such conditions, we might expect the president to favor her own party. Indeed, country experts have pointed to a number of cases in which presidents have intervened in the government formation process to the benefit of their own party (Strøm, Budge, and Laver 1994). ${ }^{2}$

- Presidential Party Hypothesis: The party of the president is more likely to be chosen as the PM party than other parties.

\section{Importance of the Bargaining Context}

The ability of strategic actors, such as the incumbent PM and the head of state, to influence PM party choice depends on the context in which coalition negotiations take place. For example, the extent to which a president can influence government formation depends on how she is elected and on whether there is an investiture vote. While a directly elected president has her own independent mandate from the people, an indirectly elected president is somewhat beholden to her party for her position. As a result, an indirectly elected president has a greater incentive to influence the choice of PM party to the benefit of her own party than a directly elected president. ${ }^{3}$ However, the ability of any president, no matter how she is elected, to influence the choice of PM party is constrained in countries where the government must pass an investiture vote. This is because any proposed government (or PM party) must enjoy a higher level of explicit support in the legislature when there is an investiture vote (Bergman 1995). When there is an investiture vote, the onus is on the government to demonstrate that it is supported by a legislative majority. In contrast, when there is no investiture vote, the onus

\footnotetext{
${ }^{2}$ We suspect that nonpartisan presidents and, indeed, monarchs also hold political preferences that might lead them to intervene in the government formation process from time to time (Golder 2010; Kristinsson 1999). Without an obvious partisan affiliation, though, we do not have a strongly reliable indicator as to which legislative party they would advantage.

${ }^{3}$ To some extent, our claim here contradicts the conventional wisdom that directly elected presidents are more politically active due to their perceived greater legitimacy (Kang 2009). In her recent book, Tavits (2009) also challenges this conventional wisdom. However, she concludes that presidential activism, as measured by the proportion of nonpartisan ministers in the government, has nothing to do with how a president is elected but instead depends on whether the president's party is in the government or not. As our theoretical framework indicates, though, whether the president's party is in the government or opposition may itself be influenced by how the president is elected.
}

is on the legislature to show that the government is not tolerated. This distinction between being supported and tolerated suggests that investiture votes constrain the ability of presidents to influence the choice of PM party. To our knowledge, previous studies of presidential activism have yet to incorporate institutional constraints such as investiture votes.

- Presidential Constraints Hypothesis: The party of the president is most likely to be chosen as the PM party when the president is indirectly elected and there is no investiture vote. The likelihood that the presidential party will be the PM party declines (and may go to zero) if the president is directly elected or if there is an investiture vote.

In a recent article, Martin and Stevenson (2010) challenge the view that incumbents always enjoy an advantage in the government formation process, arguing that any incumbency advantage is context dependent. Although Martin and Stevenson focus on incumbent governments as a whole, the logic underpinning their argument can, to a large extent, be applied to the choice of PM party. The literature on cabinet termination implies that the ability of the incumbent PM to get reselected as the prime minister depends on how her government terminated. In particular, it is likely to depend on whether her government ended due to public conflict, such as a parliamentary defeat, intracabinet conflict, or intraparty conflict, or whether her government ended for nonconflictual, technical reasons, such as the death of a PM or a constitutionally mandated election. It should be the case that the incumbent PM party is more likely to be chosen as the new PM party if the previous government did not end in conflict. This is because public conflict signals at least some dissatisfaction with the incumbent government and possibly with the incumbent PM as well.

- Termination Conflict Hypothesis: The party of the incumbent PM is more likely to be chosen as the PM party if the previous government did not end in public conflict.

The ability of the incumbent PM to influence government formation also depends on her performance and that of her coalition partners while in office. ${ }^{4}$ Obviously, a good performance while in office should translate into a

\footnotetext{
${ }^{4}$ Martin and Stevenson (2010) argue that the ability of incumbents to influence government formation also depends on whether there is a "continuation rule." The concept of a continuation rule has been interpreted in at least two different ways in the literature: (1) the incumbent government gets to stay in office until replaced, or (2) the incumbent government has the right to make the first cabinet proposal. We do not investigate continuation rules here because a close examination of constitutional sources casts doubt on their
} 
large seatshare, which, in turn, should increase the probability of being reselected as the new PM. However, there are reasons to suspect that a good performance will help the incumbent PM party above and beyond its electoral effect on party size (Martin and Stevenson 2010, 508). For example, there may be a sense, especially among the electorate, that an incumbent PM who has done well deserves to continue. Other parties may be willing to allow such an incumbent to continue, particularly if they believe that the electorate will punish them for not doing so. This suggests that the performance of the government as a whole, and, in particular, the performance of the PM party, will affect the ability of the incumbent PM to be reselected.

- Government Performance Hypothesis: The party of the incumbent PM is more likely to be chosen as the PM party if the performance of the incumbent government was good.

- Incumbent PM Performance Hypothesis: The party of the incumbent PM is more likely to be chosen as the PM party if its performance in office was good.

\section{Empirically Modeling the Choice of Prime Ministerial Party}

To date, the standard approach employed to evaluate hypotheses about PM party choice has been to treat parties as the unit of analysis and use a logit model to evaluate the likelihood that a party obtains the prime ministership (Isaksson 2005; Mattila and Raunio 2004; Warwick 1996). This approach is inappropriate, though, because it treats each potential PM party as independent of all the others and fails to recognize that only one party in any given selection opportunity can obtain the prime ministership.

conceptual usefulness and even their very existence. Undermining their conceptual usefulness is the fact that virtually all written constitutions, explicitly or implicitly, state that the incumbent government remains in place in a caretaker capacity until legally replaced by a duly mandated government. Indeed, the constitutions in the three countries usually identified as having a continuation ruleDenmark, Norway, and Sweden - are not unusual in this respect. The existence of continuation rules is called into question due to the fact that the Danish, Norwegian, and Swedish constitutions make no reference to the incumbent government getting the first shot at forming a cabinet. The most detailed volume on the rules governing government formation in Europe (Müller and Strøm 2000) also makes no reference to any form of continuation rule in these three countries.

\section{Conditional Logit and Its Limitations}

A more appropriate strategy is to treat each PM party selection opportunity as the unit of analysis and to estimate the probability that each party out of the set of all legislative parties obtains the prime ministership. One possibility is to use McFadden's (1974) conditional logit (CL) model. In this model, the probability that party $j$ gains the prime ministership given $K$ legislative parties in selection opportunity $i$ is given by:

$$
P_{i j}=\frac{e^{x_{i j} \beta}}{\sum_{k=1}^{K} e^{x_{i k} \beta}}
$$

where $\beta$ represents a vector of coefficients and $x_{i k}$ represents a matrix of independent variables associated with PM alternative $k$ in selection opportunity $i$. Bäck and Dumont (2008) and Kang (2009) have recently provided analyses of PM party choice that employ a conditional logit model.

Although the adoption of the CL model represents an advance in the study of PM party choice, it remains a flawed empirical strategy because it cannot deal with unobserved heterogeneity and makes the restrictive independence of irrelevant alternatives (IIA) assumption. Country experts regularly point out that case-specific contextual factors that are difficult or impossible to quantify, such as personality clashes and ad hoc critical events, can have a significant impact on PM party choice (Laver and Schofield 1990, 195-215). More generally, qualitative researchers are often concerned with causal complexity, where the effect of any one variable may depend on which other contextual factors are present or absent (Braumoeller 2003; Ragin 1987). In our case, the concern is that observed variables that can be crucially important for PM party choice in some situations might be largely irrelevant or even obstacles in others because of these idiosyncratic and case-specific contextual factors.

If these contextual factors could be observed (and measured), then the conditional relationship between our observed variables and PM party choice could be captured through the use of interaction terms. Unfortunately, heterogeneity in how our observed variables influence the choice of PM party may in many cases be caused by characteristics of the particular selection opportunity that are either unobserved or difficult to measure in a reliable and systematic fashion. As an illustration of this, consider how various strategic, ideological, and personal factors have placed the party with the most seats at a disadvantage in many countries when vying for the prime ministership. 
As part of its electoral strategy, the largest party in Ireland, Fianna Fáil, categorically refused to form coalition governments until 1989. A consequence was that it stayed in opposition on a number of occasions and Fine Gael, a smaller party, won the prime ministership by forming a coalition with other parties (Laver and Schofield 1990). Similarly, the social-democratic Partij van de Arbeid (PvdA) followed a strategy of political polarization in the Netherlands from the 1960s to the 1980s. The result was that in 1977 and 1982, the PvdA "suffered the trauma of a 'defeat in a victory': the PvdA became the largest party in the elections, but lost the subsequent coalition formation" (Timmermans and Andeweg 2000, 367-68). The PvdA's attempts to form coalitions with the center-right Christen-Democratisch Appèl (CDA) and the conservative-liberal Volkspartij voor Vrijheid en Democratie (VVD) all failed due to ideological and personal conflicts.

In some cases the factors working against the largest party are even more idiosyncratic. Prior to the 1997 legislative elections, for example, the Norwegian PM Thorbjørn Jagland declared that his Labor government would resign if it received less than $36.9 \%$ of the national vote (the percentage Labor had won in the previous election). Although the elections resulted in the Labor Party being the plurality winner, the fact that it won only $35 \%$ of the vote effectively ruled it out as a possible governmental party. The end result was the installation of a minority coalition government that controlled only about a quarter of the seats in parliament. As Strøm notes, "[h]ad Jagland not committed himself to his game plan, he most likely could have continued in office after the election" $(2000,284)$.

As these examples illustrate, variables traditionally seen as being key determinants of PM party choice, such as largest party status, may have little impact on the choice of PM party due to case-specific contextual factors that are hard to observe or measure. Typically, quantitative scholars have assumed that the only meaningful variation across cases is captured by the observed variables in their models and, therefore, that idiosyncratic contextual factors, such as Jagland's 1997 preelectoral declaration in Norway, can be safely relegated to a random error term that is independently and identically distributed (IID) across observations. However, this assumption is problematic on both substantive and methodological grounds.

Substantively, we wish to relax the assumption that all PM selection opportunities are homogeneous, with the only interesting variation captured by our observed variables. Although we cannot observe all of the contextual factors that influence the choice of PM party, understanding how these unobserved factors introduce variation into the effects of the variables that we can observe is valuable substantive information. By allowing heterogeneity and causal complexity to play a role in our empirical model, we help to bridge the gap between general theoretical models and case-specific studies (Beck and Katz 2007; Western 1998).

Methodologically, ignoring unobserved heterogeneity in the effects of our observed variables is likely to violate the assumption that the errors in the CL model are independently and identically distributed across parties. In particular, unobserved heterogeneity is likely to mean that the error terms associated with the parties in each selection opportunity will be negatively correlated, as increases or decreases in the influence of the observed variables will systematically advantage some parties and disadvantage others. This is important because violations of the assumption that the errors are IID lead to inconsistent parameter estimates.

Note that a failure to address any violations of the IID assumption for our error term will also cause us to estimate incorrect substitution patterns between parties. In other words, we will incorrectly estimate how the probability that a party gains the prime ministership changes as its characteristics, or those of other parties, change. This follows from the fact that the IID error term in the CL model is the basis for the well-known IIA assumption, which requires that a change in the attributes of one potential PM party changes the probabilities of choosing the other parties in a way that preserves the ratios of probabilities between parties. That is, if party A is estimated to be twice as likely to win the prime ministership as party $\mathrm{B}$, then IIA requires that this must remain true no matter how the attributes of party $\mathrm{C}$ might change. If the IIA assumption is violated and we fail to address it, then our coefficient estimates will be inconsistent and any counterfactual estimates we undertake will be suspect.

\section{Mixed Logit}

To address these substantive and methodological concerns with unobserved heterogeneity and IIA violations, we employ a random coefficient mixed logit (MXL) model in our empirical analyses (Glasgow 2001; McFadden and Train 2000; Train 1998). Substantively, we want to specify a model where the effects of the independent variables are allowed to vary across PM selection opportunities. For example, we want to allow for the possibility that the largest party might be strongly advantaged in one selection opportunity but not advantaged or even disadvantaged in another. We use a random coefficients setup where the independent variables have a mean effect $\beta$ that is adjusted upward or downward by some amount 
$\eta_{i}$ in each PM selection opportunity $i$. If we could observe this adjustment for each PM selection opportunity, then the probability that party $j$ is selected to hold the prime ministership in selection opportunity $i$ is simply the conditional logit probability from equation (1), with each probability adjusted by adding $\eta_{i}$ to $\beta$ :

$$
P_{i j}=\frac{e^{x_{i j} \beta+x_{i j} \eta_{i}}}{\sum_{k=1}^{K} e^{x_{i k} \beta+x_{i k} \eta_{i}} .}
$$

Of course, $\eta_{i}$ is not actually observed because it is a function of the unobserved or unmeasured factors that affect PM party choice. We solve this problem by specifying a joint probability distribution $g(\eta \mid \Omega)$ for $\eta$, where $\Omega$ are the fixed parameters of the distribution $g$ - this specifies the distributions of our random coefficients. We can then obtain the unconditional probability of winning the prime ministership for each party by integrating over all possible values of $\eta$ weighted by the density function of $\eta$ as given by $g$ :

$$
P_{i j}=\int\left[\frac{e^{x_{i j} \beta+x_{i j} \eta_{i}}}{\sum_{k=1}^{K} e^{x_{i k} \beta+x_{i k} \eta_{i}}}\right] g(\eta \mid \Omega) d \eta .
$$

This is the mixed logit, so named because the probabilities are a mixture of CL probabilities, each with different values for the $\eta$ s and a weight determined by the mixing distribution $g$. Estimating this mixed logit gives us $\beta$ and $\Omega$-the means and covariance matrix of our random coefficients.

In our empirical analysis, we specify our random coefficients to be uncorrelated normal distributions with the mean of each coefficient given by $\beta$ and the variance of each coefficient given by the appropriate element in $\Omega$. We choose normal distributions because they allow for the possibility that the effects of our covariates may be positive in some settings but negative in others. This is important because we have no a priori reason to believe that any of our covariate effects will always be positive or negative. ${ }^{5}$ Note that while $\eta$ varies across PM selection opportunities, it does not vary across parties in a single selection opportunity. This introduces correlation across parties into the factors that affect the probability

\footnotetext{
${ }^{5}$ Other distributions that allow for covariate effects to be positive or negative include the triangular and uniform distributions. Previous studies indicate that these distributions almost always produce similar substantive effects as the normal distribution (Hensher and Greene 2003, 148). It turns out that this is also the case here (see Table 3 in online Appendix A).
}

that a party wins the prime ministership, thereby relaxing the IIA assumption even if the covariance matrix of $g$ is diagonal.

In general, mixed logit models cannot be estimated via standard maximum likelihood techniques because the integral for the choice probabilities in equation (3) has no closed-form solution. Instead, MXL models are estimated via maximum simulated likelihood. For each PM selection opportunity, a value for $\eta_{i}$ is drawn from $g(\eta \mid \Omega)$ and used to calculate $\hat{P}_{i j}$, the conditional choice probability in equation (2). This process is repeated $R$ times and the integration over $g(\eta \mid \Omega)$ is approximated by averaging over the $R$ conditional choice probabilities for each PM selection opportunity. A simulated log-likelihood function is then created from these simulated probabilities and is maximized with conventional maximum likelihood techniques.

\section{Empirical Analysis}

We first describe the data employed to test our hypotheses. We then present and discuss the results.

\section{Data and Measurement Issues}

To create our data set, we began with all the governments identified by the Comparative Parliamentary Democracy Archive (Strøm, Müller, and Bergman 2008). Thus, we began with 424 different governments in 17 nonpresidential Western European democracies from 1945 to 1998. The countries included were Austria, Belgium, Denmark, Finland, France, Germany, Greece, Iceland, Ireland, Italy, Luxembourg, the Netherlands, Norway, Portugal, Spain, Sweden, and the United Kingdom. We then dropped 15 governments because the data on legislative seats were either missing or incorrect, leaving us with 409 governments for Western Europe. To these governments, we added an additional 123 governments from a new data set that we collected covering 11 Eastern European countries from their democratic transitions around 1990 through 2008. The East European countries included were Bulgaria, Croatia, Czech Republic, Estonia, Hungary, Latvia, Lithuania, Poland, Romania, Slovakia, and Slovenia.

In line with the existing literature, we dropped all nonpartisan (27) and caretaker (9) governments. We dropped another 66 cases in which a single party controlled a legislative majority because we could not distinguish between the effects of largest party status and majority status-majority status is a perfect predictor of PM party choice, making maximum likelihood estimation of a coefficient on a majority status variable impossible. 
To evaluate hypotheses about PM party choice, we must identify situations in which a new PM party might actually be chosen. Given how the literature codes governments, the emergence of a new government does not automatically signal a new PM party selection opportunity. According to the standard definition, a new government occurs when there is a change in the set of cabinet parties, the identity of the PM changes, or there is a general election. The issue here concerns new governments that result from changes in the party composition of the cabinet but that are not characterized by a change in the PM, legislative elections, parliamentary defeat, or a government resignation. Although the identity of the government clearly changes whenever a party joins or leaves an existing cabinet, these cases do not, in and of themselves, represent situations in which party leaders rebargain over the prime ministership. An obvious consequence of including these governments in analyses of PM party choice, as previous studies have done, is that scholars necessarily overestimate the importance of being the incumbent PM party. In recognition of this fact, we drop a further 61 cases in which a new government emerged but in which there was no opportunity to select a new PM party. ${ }^{6}$

After these omissions, we are left with 369 PM party selection opportunities and 2,412 potential PM parties. Our data set is considerably larger than those used in previous studies and is the first to include information on PM party choice in Eastern Europe.

We created a number of measures to test our hypotheses. Largest Party, Incumbent PM, and Investiture are dichotomous variables indicating whether a party is the largest legislative party, whether a party is the incumbent PM party, and whether there is an investiture vote. Party Size measures the percentage of legislative seats controlled by each party. The data for these variables come from the Comparative Parliamentary Democracy Archive (CPDA) for Western Europe and the Comparative Manifestos Project (Klingemann et al. 2006) for Eastern Europe. President Party and Direct Elections are dichotomous variables indicating the party of the president and whether the president is directly elected (Golder 2005; Kang 2009).

Median Party is a dichotomous variable indicating the median ideological party, i.e., the party containing the median legislator when parties are aligned along the leftright continuum. For Western Europe, the median party

\footnotetext{
${ }^{6}$ Some will argue that these dropped governments represent cases in which the parties could have rebargained over the prime ministership and that they should therefore be included. We should note that the results from robustness checks where we include these governments, as well as the nine caretaker governments that were also omitted, are essentially the same as those we present here except that, as one would expect, the effect of being the incumbent PM party is slightly stronger (see Table 4 in online Appendix B).
}

is identified by the CPDA country experts. For Eastern Europe, we identified the median party using the estimated left-right party placements provided by the Comparative Manifestos Project (CMP). We should note that there are problems with using CMP data to identify the median party. For example, one is that the CMP data often provide ideological information for electoral coalitions rather than for individual parties. Given the limitations of the CMP data (Benoit and Laver 2007), we would have preferred to use expert judgments to identify the median party for all of our cases. Unfortunately, such data do not exist for all of our Eastern European observations. The bottom line is that we believe that the identity of the median party is more reliably measured in our Western European cases than in our Eastern European ones.

Conflict Termination is a dichotomous variable indicating whether the previous government ended due to public conflict. Governments are coded as ending in public conflict if they terminate because of a parliamentary defeat, intracabinet conflict, or intraparty conflict. Governments do not end in public conflict if they terminate because of some technical or constitutional reason, such as when a government's constitutionally mandated term comes to an end. Whether a government that ends with early elections is coded as terminating in conflict depends on the circumstances surrounding its demise. Although most terminations that result in early elections are conflictual, this is not always the case. For example, some governments simply call early elections because they hope to take advantage of favorable electoral conditions. Data on this variable for Western Europe come from the CPDA, while data for Eastern Europe come from a wide range of sources, including Keesings and the European Journal of Political Research country reports.

PM Performance and Cabinet Performance measure the performances of the incumbent PM party and its coalition partners. A common way to conceptualize "performance" is in terms of economic performance. However, operationalizing performance with an economic indicator is problematic for at least two reasons. First, economic indicators, such as the unemployment rate, do not allow us to distinguish between the performance of the incumbent PM party and that of the government as a whole. Second, the relevant indicator of economic performance varies across regions, countries, and time periods. For instance, unemployment might be the primary concern in some countries and time periods, whereas inflation might be the predominant economic issue in others. Because of these problems, we follow a long line of research in the government accountability literature and conceptualize performance in terms of electoral performance. More specifically, we measure PM Performance and 
Cabinet Performance as the change in the percentage of seats controlled by the incumbent PM party and the cabinet since the last selection opportunity (Martin and Stevenson 2010, 510). An appealing feature of this approach is that it captures both economic and noneconomic aspects of a government's performance. The obvious underlying assumption here is that electoral outcomes are, at least partially, determined by government performance. Recent research suggests that this is not an unreasonable assumption (Duch and Stevenson 2008).

\section{Results and Interpretation}

We estimated six different models. Models 1 and 2 focus solely on party-specific variables such as party size and ideology. Models 3 and 4 take account of the privileged roles played by the president and the incumbent PM. Finally, Models 5 and 6 add contextual variables that constrain the ability of these key strategic actors to influence the choice of PM party. To evaluate whether there are significant differences in the factors influencing PM party choice between Western and Eastern Europe, we interact all but two of the independent variables with a dichotomous regional variable. ${ }^{7}$ For each model, we estimate both the mean coefficient and its standard deviation for all of the independent variables except the interaction terms with the regional dummy variable.

Each of the six models was estimated using our whole sample. However, to ease interpretation and presentation, we present our results as if we had split the sample into those cases from Western Europe and those cases from Eastern Europe. The results for Western Europe are shown in Table 1 and the results for Eastern Europe are shown in Table 2. The last column in Table 2 indicates whether the effects of the variables for Eastern Europe are significantly different $(\mathrm{p}<0.10)$ from those for Western Europe based on Model 6.

\footnotetext{
${ }^{7}$ We do not interact President Party $\times$ Direct Elections or President Party $\times$ Investiture with the dichotomous regional variable due to unavoidable limitations with our Eastern European observations. Specifically, there is only one selection opportunity in Eastern Europe in which the president's party is chosen as the PM party and the president is directly elected, and there are no selection opportunities in which the president's party is chosen without an investiture vote. In effect, there is insufficient variation on President Party $\times$ Direct Elections and President Party $\times$ Investiture to reliably estimate their separate effects in Eastern Europe; instead, we estimate a single effect for each of these variables across both regions. Given that the estimated coefficients on these interaction terms are driven almost entirely by variation in Western Europe, we caution readers against using them to draw inferences about how investiture votes and direct elections constrain the ability of presidents to influence PM party choice specifically in Eastern Europe. To highlight this point, the relevant cells in Table 2 are shown in gray.
}

As we noted earlier, media and scholarly accounts of the government formation process often focus on the largest legislative party. This is hardly a surprise given that the largest party obtains the prime ministership in $72.8 \%$ and $77.5 \%$ of the selection opportunities in Western and Eastern Europe, respectively. However, our models reveal that factors besides largest party status play a crucial role in PM party choice. Indeed, likelihood ratio tests comparing our models to a similarly specified model that includes Largest Party as the only independent variable emphatically reject the assertion that only the identity of the largest party matters.

For example, simply considering the identity of the largest party does not tell us whether these parties obtain the prime ministership because they are the largest party or simply because they happen to be a large party. The results of our empirical analysis provide considerable support for the Party Size Hypothesis that parties are more likely to be selected as the PM party the larger their legislative seatshare. This can be seen by the positive and statistically significant mean coefficient on Party Size in all six models shown in Tables 1 and 2. Party size clearly matters, but is there a bonus for being the largest party above and beyond simply being a large party?

The fact that the mean coefficient on Largest Party is positive and statistically significant in all six models shown in Table 1 but insignificant in all six models in Table 2 indicates that there is a largest party bonus on average in Western Europe but not in Eastern Europe. Note, though, that the standard deviation of the random coefficient on Largest Party is always large relative to its mean and statistically significant. This indicates that the advantage enjoyed by the largest party when seeking the prime ministership varies considerably from one selection opportunity to another. For example, the fact that the distribution of the coefficient on Largest Party in Model 6 in Table 1 has a mean of 2.11 and a standard deviation of 4.73 means that $67.2 \%$ of the distribution is above zero and $32.8 \%$ is below zero. Practically speaking, this means that the largest party is advantaged a little over twothirds of the time in Western Europe but disadvantaged a little under a third of the time. The estimated mean and standard deviation of the coefficient on Largest Party in Model 6 in Table 2 indicates that the largest party is more likely to become the PM party $57.2 \%$ of the time in Eastern Europe but less likely to become it $42.8 \%$ of the time.

Overall, our results on party size suggest that things are more complex than media accounts or conventional scholarly wisdom would have us believe when it comes to PM party choice. Although it clearly helps to be a large party when competing for the prime ministership, it is not 


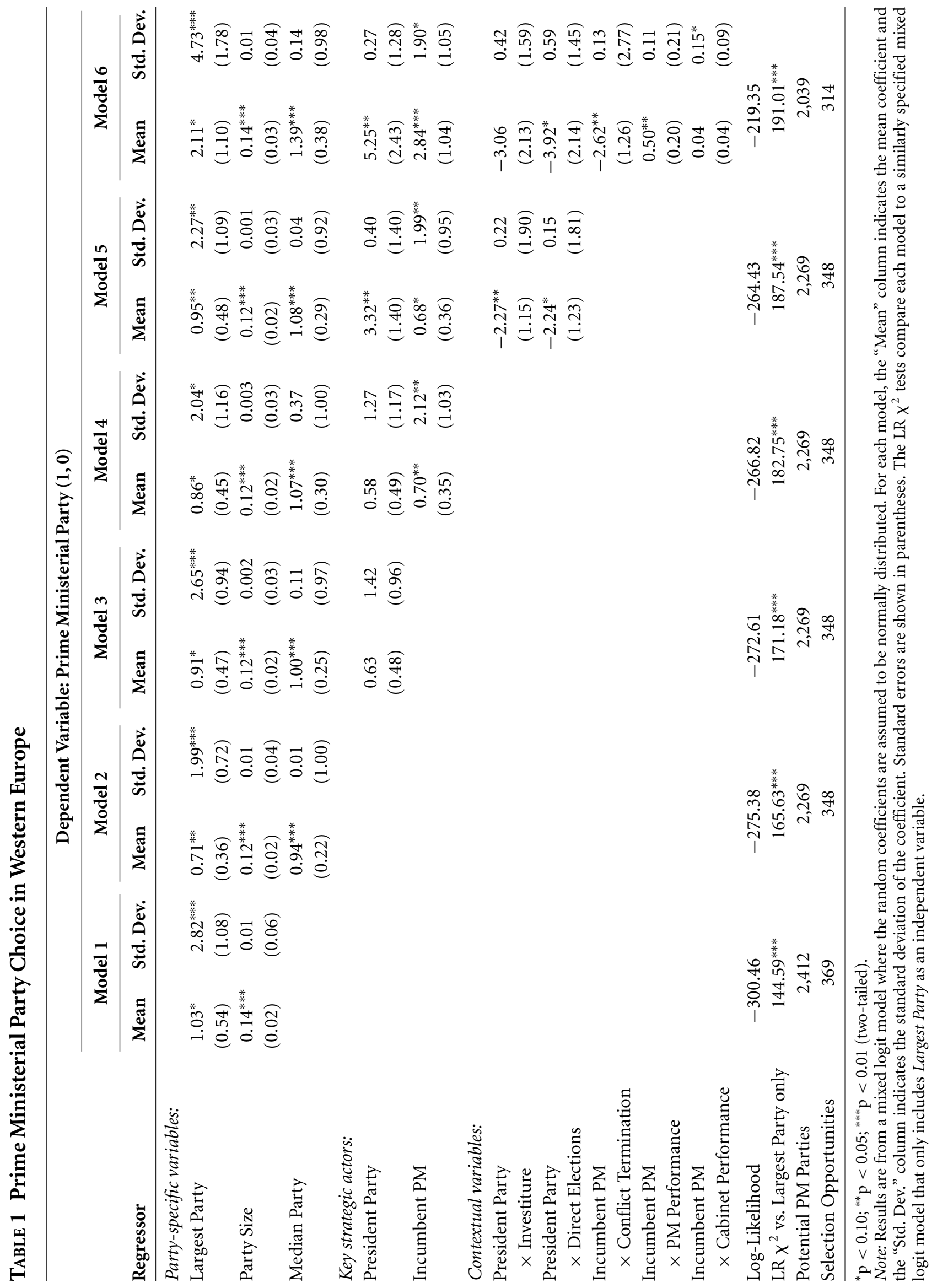




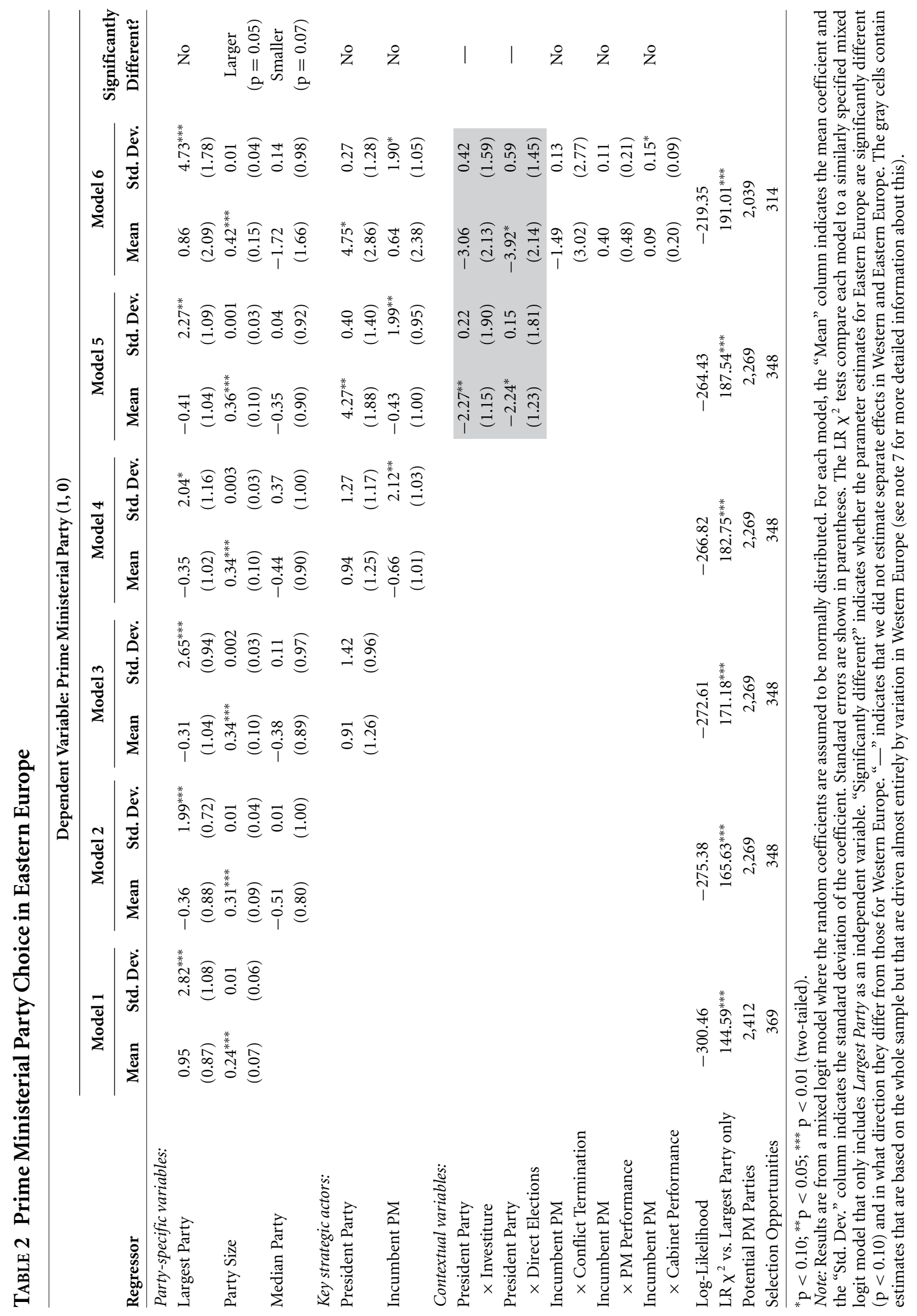


always the case that the largest party holds an advantage when it comes to obtaining the prime ministership. As our results indicate, there is considerable unobserved heterogeneity surrounding the effect of being the largest party. Indeed, there appear to be many situations in which, controlling for its legislative size, the largest party is actually disadvantaged when it comes to obtaining the prime ministership. Note that this does not necessarily mean that it is the largest party status itself that causes this disadvantage-rather, unobserved characteristics of the selection opportunity, exemplified by the anecdotal evidence from Ireland, the Netherlands, and Norway that we discussed earlier, influence the probability that the largest party will attain the prime ministership. Our results show that in many cases, these kinds of case-specific and ad hoc factors can augment, dilute, or even reverse the advantage we would expect for the largest party.

Existing studies suggest that the median party is more likely to be chosen as the PM party than other parties. However, our results suggest that this may only be the case in Western Europe-the mean coefficient on Median Party is positive and statistically significant in all of the models in which it is included in Table 1 (Western Europe) but negative and insignificant in the equivalent models in Table 2 (Eastern Europe). One explanation for this difference has to do with the dimensionality of the policy space in the two regions. Recall that the argument as to why the median party is in a favorable position with respect to the other parties rests on the assumption that the policy space is one-dimensional. Although the assumption of a single-issue dimension is well supported in Western Europe, it is less clear that a single issue dimension accurately captures the policy space in Eastern Europe (Benoit and Laver 2006). As a result, we might not expect the median party to have a higher probability of obtaining the prime ministership than other parties in Eastern Europe.

An alternative explanation, though, has to do with how we identify the median party. Recall that median parties in Western Europe are identified by country experts, whereas those in Eastern Europe are identified using data from the Comparative Manifestos Project. As we indicated earlier, there are good reasons to believe that median parties are more reliably identified in Western $\mathrm{Eu}$ rope than in Eastern Europe. Given this, readers should be somewhat cautious in concluding that being the median party does not help one obtain the prime ministership in Eastern Europe. Some support for this explanation comes from the fact that median parties in Western Europe are no longer advantaged when we use the less reliable CMP data to identify them.

Presidents in nonpresidential democracies are often seen as being above the fray of day-to-day political competition. To some extent, this view of presidents is supported by the results in Models 3 and 4 where President Party is included additively - the mean coefficient on President Party is insignificant, thereby indicating that the president's party is no more likely to be chosen as the PM party than other parties. As we have argued, though, the desire and ability of presidents to influence the choice of PM party depends on the context in which coalition negotiations take place. In particular, presidents have a greater incentive to help their own party when they are indirectly elected and are better placed to help them when there is no investiture vote. This reasoning receives considerable support from Models 5 and 6 where President Party is included interactively. Specifically, the results show that the president's party is more likely to be chosen as the PM party if the president is indirectly elected and there is no investiture vote. This is indicated by the positive and significant mean coefficient on President Party. The probability that the president's party obtains the prime ministership declines if the president is directly elected and/or if there is an investiture vote. This is indicated by the negative and significant coefficients on President Party $\times$ Investiture and President Party $\times$ Direct Elections. Indeed, the magnitude of the mean coefficients on these interaction terms means that the statistically significant positive effect of being the president's party essentially disappears if the president is either directly elected or if there is an investiture vote.

Previous studies all find evidence of an incumbency advantage when it comes to PM party choice (Bäck and Dumont 2008; Mattila and Raunio 2004; Warwick 1996). However, the results from Models 4 and 5, in which Incumbent $P M$ is included additively, show that while an incumbency advantage exists, on average, in Western Europe, this is not the case in Eastern Europe. This is indicated by the positive and statistically significant mean coefficients on Incumbent PM in these models in Table 1 (Western Europe) and the negative and statistically insignificant mean coefficients on Incumbent PM in these models in Table 2 (Eastern Europe).

Importantly, the standard deviations on Incumbent $P M$ in Models 4 and 5 are statistically significant in both Western and Eastern Europe. This indicates that there is considerable unobserved heterogeneity around the effect of being the incumbent PM party. For example, the fact that the mean coefficient on Incumbent PM is 0.70 with a standard deviation of 2.12 in Model 4 in Table 1 suggests that the incumbent PM party is advantaged when seeking the prime ministership $62.9 \%$ of the time in Western Europe but disadvantaged $37.1 \%$ of the time. The importance attached to being the incumbent is almost the exact opposite in Eastern Europe, where the incumbent PM party is advantaged only $41.5 \%$ of the time. As with largest party status, unobserved characteristics of the PM 
selection opportunity mean that the incumbent PM party is not always advantaged as previous studies have suggested.

As we noted earlier, there are several contextual factors that might explain the heterogeneity in the effect of Incumbent PM found in Models 4 and 5. These contextual factors are incorporated in Model 6. We focus initially on the results for Western Europe. The first thing to note is that the incumbent PM party is, on average, more likely to gain the prime ministership when the previous cabinet ends without public conflict and when it and its coalition partners see no change in their legislative seatshares. This is indicated by the positive and statistically significant mean coefficient on Incumbent Party. As predicted by the Termination Conflict Hypothesis, this positive effect declines and indeed disappears if the previous cabinet ends in public conflict. This is indicated by the negative and statistically significant mean coefficient on Incumbent PM $\times$ Conflict Termination. To a large extent, this result parallels the finding in Martin and Stevenson's (2010) recent analysis of Western European governments that coalitions ending in conflict are less likely to be reconstituted with the same member parties than coalitions that end without conflict. In other words, how a cabinet terminates appears to affect not only the likelihood that the incumbent government as a whole is returned to office but also the likelihood that the incumbent PM party is reappointed (as part of any government).

As predicted by the PM Performance Hypothesis, incumbent PM parties are more likely to retain the prime ministership if they gain legislative seats. Evidence for this comes from the positive and statistically significant coefficient on Incumbent PM $\times$ PM Performance. Contrary to the Government Performance Hypothesis, incumbent PM parties do not, on average, have a greater probability of winning the prime ministership when the government as a whole gains legislative seats. ${ }^{8}$ This is indicated by the statistically insignificant coefficient on Incumbent $P M \times$ Cabinet Performance. Note, though, that the standard deviation on this last product term is statistically significant, suggesting that the performance of the cabinet as a whole may help (or hurt, perhaps by creating stronger competitors) the incumbent PM party in some circumstances. Taken together, these results demonstrate that contextual features of the bargaining environment can have a significant impact on the choice of PM party. It is worth noting, however, that the inclusion of these

\footnotetext{
${ }^{8}$ Martin and Stevenson (2010) find that the incumbent government is more likely to be returned to office when it gains legislative seats. Unlike in our analysis, they do not distinguish between the performance of the incumbent PM party and that of the incumbent government as a whole.
}

contextual features is not sufficient to fully account for the unobserved heterogeneity in the effect of Incumbent Party that we found in Models 4 and 5-the standard deviation on Incumbent Party remains statistically significant in Model 6.

What about the importance of the incumbent PM party in Eastern Europe? Overall, there is little to suggest that there is ever an incumbency advantage in Eastern Europe, irrespective of the incumbent PM party's electoral performance and how the previous cabinet terminated. This is because the mean coefficients on Incumbent PM and the various product terms that include this variable in Table 2 never reach conventional levels of statistical significance. We should note, though, that these coefficients all have the predicted sign and are not significantly different from the equivalent coefficients for Western Europe.

One criticism of existing theories of government formation is that they have been built and tested with Western Europe in mind. This naturally raises the question as to whether these theories apply equally well to other regions of the world. Our analysis throws light on this issue. Despite social, economic, and cultural differences between Western and Eastern Europe, the evidence presented in Tables 1 and 2 indicates that there are, on the whole, few differences in how PM parties are selected in the two regions. As the last column in Table 2 illustrates, only two of the eight coefficients in Model 6 that we allow to vary are statistically different across the two regions: (1) the coefficient on Party Size is significantly larger in Eastern Europe $(\mathrm{p}<0.05)$ and $(2)$ the coefficient on $\mathrm{Me}$ dian Party is significantly smaller $(\mathrm{p}<0.08)$. In other words, being a large party matters more in Eastern Europe for gaining the prime ministership but being the median ideological party matters less. We suspect that noninstitutional contextual factors such as the existence of communist successor parties probably do play an important role in the choice of PM party in Eastern Europe. However, our results suggest that the failure of existing cross-national theories to incorporate such noninstitutional contextual factors is not as problematic as some suggest.

Methodologically, the statistically significant standard deviations on some of the MXL coefficients indicate the presence of unobserved heterogeneity, a violation of the CL assumptions that the error term is IID and that IIA holds. In other words, employing a CL model, rather than an MXL model, to examine PM party choice would produce inconsistent parameter estimates and inaccurate estimates of choice probabilities and substitution patterns. Online Appendix D compares a conditional logit model of PM party choice to the mixed logit presented here, 
FIGURE 1 The Substantive Importance of Largest Party Status (Netherlands 1994)

(a) Heterogeneity in the Effect of Largest Party Status on the Probability of Gaining the Prime Ministership

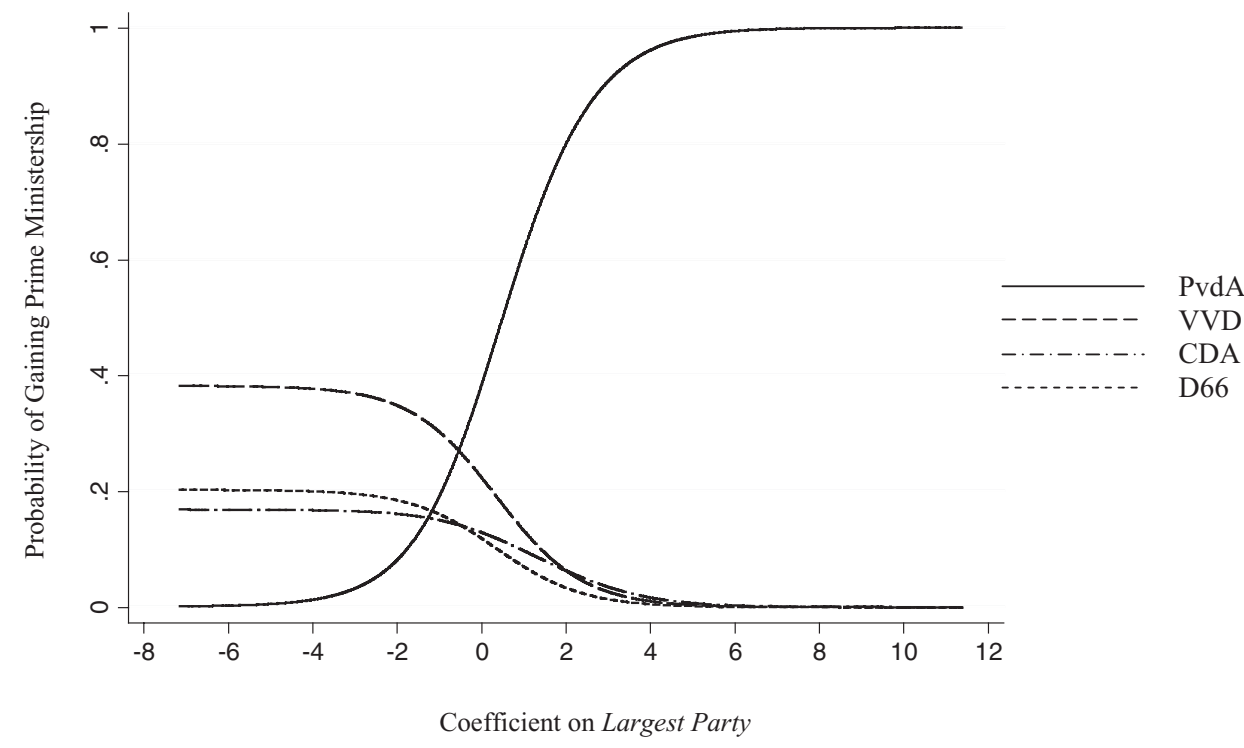

(b) Changing the Identity of the Largest Party on the Probability of Gaining the Prime Ministership

\begin{tabular}{|c|c|c|c|c|c|c|c|}
\hline \multirow[b]{3}{*}{ Party } & \multicolumn{7}{|c|}{ Largest Party and Party Size } \\
\hline & \multirow{2}{*}{$\begin{array}{c}\text { PvdA } \\
\text { Predicted } \\
\text { Probability }\end{array}$} & \multicolumn{2}{|c|}{$\mathrm{PvdA} \rightarrow \mathrm{CDA}$} & \multicolumn{2}{|c|}{$\mathrm{PvdA} \rightarrow \mathrm{VVD}$} & \multicolumn{2}{|c|}{$\mathrm{PvdA} \rightarrow \mathrm{D} 66$} \\
\hline & & $\begin{array}{l}\text { Predicted } \\
\text { Probability }\end{array}$ & $\begin{array}{l}\text { Change in } \\
\text { Probability }\end{array}$ & $\begin{array}{l}\text { Predicted } \\
\text { Probability }\end{array}$ & $\begin{array}{l}\text { Change in } \\
\text { Probability }\end{array}$ & $\begin{array}{l}\text { Predicted } \\
\text { Probability }\end{array}$ & $\begin{array}{l}\text { Change in } \\
\text { Probability }\end{array}$ \\
\hline PvdA & $\begin{array}{c}0.58 \\
(0.10)\end{array}$ & $\begin{array}{c}0.21 \\
(0.05)\end{array}$ & $\begin{array}{c}-0.37 * * * \\
(0.10)\end{array}$ & $\begin{array}{c}0.12 \\
(0.03)\end{array}$ & $\begin{array}{c}-0.45^{* * *} \\
(0.11)\end{array}$ & $\begin{array}{c}0.06 \\
(0.01)\end{array}$ & $\begin{array}{c}-0.51 * * * \\
(0.11)\end{array}$ \\
\hline CDA & $\begin{array}{c}0.14 \\
(0.10)\end{array}$ & $\begin{array}{c}0.44 \\
(0.11)\end{array}$ & $\begin{array}{c}0.30 * * * \\
(0.10)\end{array}$ & $\begin{array}{c}0.14 \\
(0.10)\end{array}$ & $\begin{array}{l}0.00 \\
(-)\end{array}$ & $\begin{array}{c}0.14 \\
(0.10)\end{array}$ & $\begin{array}{l}0.00 \\
(-)\end{array}$ \\
\hline VVD & $\begin{array}{c}0.12 \\
(0.03)\end{array}$ & $\begin{array}{c}0.15 \\
(0.03)\end{array}$ & $\begin{array}{c}0.03 \\
(0.02)\end{array}$ & $\begin{array}{c}0.58 \\
(0.10)\end{array}$ & $\begin{array}{c}0.45^{* * *} \\
(0.11)\end{array}$ & $\begin{array}{c}0.12 \\
(0.03)\end{array}$ & $\begin{array}{l}0.00 \\
(-)\end{array}$ \\
\hline D66 & $\begin{array}{c}0.06 \\
(0.01)\end{array}$ & $\begin{array}{c}0.08 \\
(0.02)\end{array}$ & $\begin{array}{c}0.02 \\
(0.01)\end{array}$ & $\begin{array}{c}0.06 \\
(0.01)\end{array}$ & $\begin{array}{l}0.00 \\
(-)\end{array}$ & $\begin{array}{c}0.58 \\
(0.10)\end{array}$ & $\begin{array}{c}0.51 * * * \\
(0.11)\end{array}$ \\
\hline
\end{tabular}

Note: Figure 1a illustrates the mixed logit predicted probabilities of gaining the prime ministership for the four largest parties in the 1994 Dutch PM selection opportunity using the results from Model 6 in Table 1 . The values of the covariates are set to be the same as those observed in the real-world selection opportunity, and all we vary is the value of the Largest Party coefficient from its $2.5^{\text {th }}$ percentile $(-7.15)$ to its $97.5^{\text {th }}$ percentile (11.37). In Figure $1 \mathrm{~b}$, we again present predicted probabilities for the four largest parties in the 1994 Dutch PM selection opportunity. The first column indicates the predicted probabilities for each party in the baseline scenario when the independent variables take on the actual values observed in the real-world selection opportunity. The remaining columns indicate either predicted probabilities or changes in predicted probabilities as we transfer the largest party status (and party size) from the PvdA to one of the other three parties. Standard errors are shown in parentheses. Statistically significant changes in predicted probability are indicated: ${ }^{*} \mathrm{p}<0: 10{ }^{* *} \mathrm{p}<0: 05 ;{ }^{* * *} \mathrm{p}<0: 01$ (two-tailed). “—” indicates no change in predicted probability and, hence, no estimated standard error. All estimates are based on simulations using 10,000 draws from the estimated coefficient vector and variance-covariance matrix.

illustrating our substantive and methodological points in more detail.

\section{Substantive Importance of Largest Party Status}

Of course, examining the sign and statistical significance of our coefficients tells us little about the substantive importance of our explanatory variables in determining the PM party. Here we consider the substantive effect of largest party status in Western Europe. ${ }^{9}$ As we saw earlier, the standard deviation of the random coefficient on Largest Party in Model 6 in Table 1 is statistically significant. In Figure 1a, we illustrate how this heterogeneity in the effect of largest party status affects the mixed logit

\footnotetext{
${ }^{9}$ Due to space limitations, the substantive importance of other covariates is discussed in online Appendix C.
} 
predicted probability of gaining the prime ministership in a hypothetical selection opportunity resembling the one that took place in the Netherlands in $1994 .{ }^{10}$ These predicted probabilities are obtained from equation (3) and are calculated using the estimated coefficients and covariance matrix, the draws for $\eta$ used in estimating our model, and the appropriate hypothetical values for the independent variables. Although 12 legislative parties competed for the Dutch prime ministership in 1994, we focus on the four largest parties: the PvdA, the CDA, and the VVD (described above), as well as Democraten 66 (D66). The four lines in Figure 1a indicate how the predicted probability of winning the prime ministership for each of these parties changes as we vary the magnitude of the random coefficient on Largest Party from its $2.5^{\text {th }}$ percentile (-7.15) to its $97.5^{\text {th }}$ percentile (11.37).

To give some background, the PvdA was the largest party in the Netherlands in 1994 with $24.7 \%$ of the legislative seats. The CDA was the median ideological party and the incumbent PM party. Although its government had terminated without public conflict, the CDA had seen its seatshare decline dramatically from $36 \%$ at the previous PM selection opportunity to $22.7 \%$ in this one. Together with its coalition partner (the PvdA), the CDA set a record in the number of legislative seats (32) lost by a government since the introduction of universal suffrage and proportional representation in 1917. The VVD and D66 won $20.7 \%$ and $16 \%$ of the legislative seats, respectively. The actual outcome of the 1994 Dutch government formation process was that the PvdA obtained the prime ministership and formed a three-party coalition with the VVD and D66.

Figure 1a demonstrates there is considerable heterogeneity in the predicted probabilities with which the largest party-the PvdA-and the other parties obtain the prime ministership. For example, the PvdA's predicted probability of obtaining the prime ministership effectively ranges from 0 to 1 . Indeed, the PvdA has a lower probability of winning the prime ministership than at least one other party when the Largest Party coefficient is less than -0.54 ; this occurs $28.8 \%$ of the time in PM selection opportunities resembling the one that took place in the Netherlands in 1994. Significantly, the fact that our results suggest that there are circumstances in which the VVD might realistically have obtained the prime ministership in 1994 even though the PvdA was the largest party fits with accounts of the Dutch government formation process at the time indicating that a VVD-led

\footnotetext{
${ }^{10}$ By choosing the 1994 Dutch elections, we follow in a long line of studies that have used these elections to demonstrate methodological advances in the use of discrete choice models (e.g., Alvarez and Nagler 1998; Glasgow and Alvarez 2005).
}

coalition with the D66 was a distinct possibility (Irwin $1995,76){ }^{11}$

While Figure 1a focuses on heterogeneity in the effect of largest party status on PM party choice, Figure $1 \mathrm{~b}$ examines the mean effect of largest party status. The first column of Figure $1 \mathrm{~b}$ indicates the mixed logit predicted probabilities that each of the four largest parties in this PM selection opportunity gains the prime ministership in the baseline scenario in which the independent variables take on the actual values observed in the Dutch 1994 case. The remaining columns indicate either predicted probabilities or changes in predicted probabilities as largest party status (and party size) is transferred from the PvdA to one of the other three parties.

In the baseline scenario, the PvdA has the largest predicted probability $(0.58)$ of winning the prime ministership. Although this probability always declines when we transfer the PvdA's party size and largest party status to one of the other parties, the extent to which it declines depends a great deal on the identity of the recipient party. For example, the predicted probability that the PvdA becomes the PM party declines by $0.37,0.45$, and 0.51 when we transfer the PvdA's party size and largest party status to the CDA, VVD, and D66, respectively. The changes in predicted probability that the PvdA becomes the PM party are substantively large and statistically significant in all three of the counterfactual scenarios. That party size plays an important role in the selection of the PM party is further illustrated by the fact that whichever party obtains the PvdA's party size and largest party status immediately becomes the party most likely to gain the prime ministership.

\section{Conclusion}

Although the government formation literature is one of the largest in political science, relatively little attention has been paid to the factors that influence PM party choice. That so few studies have examined the choice of PM party is somewhat puzzling given that the prime ministerial portfolio draws by far the most interest from political actors and the public alike, and that whichever party controls it enjoys a disproportionate influence when it comes to setting the agenda, making policy, and allocating office benefits. One explanation for the relative dearth of studies on PM party choice has to do with the widespread

\footnotetext{
${ }^{11}$ Also note that Figure 1 provides further evidence that the incumbent PM party is not always advantaged, as previous studies have suggested. Despite being the incumbent PM party (and the median party), the CDA's predicted probability of becoming the PM party is almost always lower than that of either the PvdA or the VVD; this is likely due to the CDA's poor electoral performance.
} 
belief that the choice of PM party is a simple function of party size. As our analysis indicates, it is much more complicated than this.

To a large extent, conventional scholarly wisdom and media accounts of government formation would have us believe that the key determinant of PM party choice is largest party status. While our analysis reveals that party size clearly matters, it is not the case that the largest party is always advantaged. For example, our results indicate that there is no largest party bonus on average in Eastern Europe. Significantly, our results also show that there is considerable unobserved heterogeneity in the effect of largest party status such that the largest party finds itself disadvantaged in many circumstances. Indeed, our analysis suggests that unobserved factors result in the largest party being at a disadvantage over $40 \%$ of the time in Eastern Europe and about a third of the time in Western Europe. These results run directly counter to the standard claim that the largest party is always advantaged when seeking the prime ministership.

Traditionally, presidents in nonparliamentary democracies have been portrayed as ceremonial figures who steer clear of the more nitty-gritty aspects of political competition. However, recent studies have challenged this view and presented evidence of presidential activism, particularly when it comes to the proportion of nonpartisan ministers in a cabinet (Amorim Neto and Strøm 2006; Schleiter and Morgan-Jones 2009a; Tavits 2009). Our analysis contributes to this new line of research by showing that presidents also play an active role in the partisan choice of PM party. Specifically, our results are consistent with the idea that indirectly elected presidents have an incentive to help their own parties gain the prime ministership but that their ability to effectively do this depends on the institutional environment in which they act.

All five previous studies of PM party choice claim that there is an incumbency advantage when it comes to winning the prime ministership. As we demonstrate, though, this is not necessarily the case. Any benefit that accrues to the incumbent PM party depends critically on dynamic features of the bargaining context. In particular, our results indicate that incumbency can be an advantage, but only when the previous cabinet ends without conflict and when the performance of the incumbent PM party is not too dismal. When cabinets end conflictually and/or when electoral performance is poor, incumbency can turn out to be a distinct liability.

Existing theories of government formation are often criticized for overlooking the potential impact of noninstitutional contextual factors that differ across countries. By explicitly comparing PM party choice in Western and
Eastern Europe, two regions with similar institutions but quite different social, economic, and cultural environments, we are able to throw some light on the strength of this criticism. On the whole, our analysis suggests that noninstitutional contextual differences across Western and Eastern Europe make little difference to the estimated effects of our covariates. The only obvious difference was that being the median ideological party matters in Western Europe but not in Eastern Europe. Even here, though, unavoidable measurement issues with identifying the median party in Eastern Europe make us reluctant to necessarily conclude that there are differences across the two regions when it comes to the impact of median party status on PM party choice.

Our use of a mixed logit represents both a substantive and methodological advance over the empirical strategies employed in previous work and should appeal to both qualitative and quantitative scholars. Qualitative scholars often question the utility of constructing general theories of government formation and testing them with cross-national statistical models because they believe that these theories and tests inevitably omit idiosyncratic casespecific factors that can have an important impact on the government formation process. Although quantitative scholars generally recognize that these types of casespecific factors can be important for things like PM party choice, they have essentially ignored them in their analyses under the presumption that doing so does not affect their results or that there are no empirical strategies to handle them. As we have demonstrated, both of these presumptions are wrong.

Ignoring unobserved heterogeneity in discrete choice settings such as that of PM party choice results in inconsistent estimates and incorrect substitution patterns that leave counterfactual analyses and substantive inferences suspect. In addition to solving various methodological problems, the mixed logit provides valuable substantive information about how unobserved contextual factors introduce variation into the effects of our observed variables that is simply not available from more traditional estimation strategies. Our approach creates common ground between qualitative and quantitative scholars, providing a way for political scientists to test cross-national theories of government formation while also taking account of case-specific contextual factors, thus advancing our understanding of who "wins" parliamentary elections.

\section{References}

Alvarez, R. Michael, and Jonathan Nagler. 1998. "When Politics and Models Collide: Estimating Models of Multiparty 
Elections." American Journal of Political Science 42(1): 5596.

Amorim Neto, Octavio, and Kaare Strøm. 2006. "Breaking the Parliamentary Chain of Delegation.” British Journal of Political Science 36(4): 619-43.

Bäck, Hanna, and Patrick Dumont. 2008. "Making the First Move: A Two-Stage Analysis of the Role of Formateurs in Parliamentary Government Formation." Public Choice 135(3-4): 353-73.

Baron, David P., and John Ferejohn. 1989. "Bargaining in Legislatures." American Political Science Review 83(4): 11811206.

Beck, Nathaniel, and Jonathan N. Katz. 2007. "Random Coefficient Models for Time-Series-Cross-Section Data: Monte Carlo Experiments.” Political Analysis 15(2): 182-95.

Benoit, Kenneth, and Michael Laver. 2006. Party Policy in Modern Democracies. London: Routledge.

Benoit, Kenneth, and Michael Laver. 2007. "Estimating Party Policy Positions: Comparing Expert Surveys and HandCoded Content Analysis." Electoral Studies 26(1): 90-107.

Bergman, Torbjörn. 1995. Constitutional Rules and Party Goals in Coalition Formation. Umeå, Sweden: Umeå University Press.

Braumoeller, Bear. 2003. "Causal Complexity and the Study of Politics.” Political Analysis 11(3): 209-33.

Duch, Raymond M., and Randolph T. Stevenson. 2008. Voting in Context: How Political and Economic Institutions Condition the Economic Vote. New York: Cambridge University Press.

Glasgow, Garrett. 2001. "Mixed Logit Models for Multiparty Elections." Political Analysis 9(2): 116-36.

Glasgow, Garrett, and R. Michael Alvarez. 2005. "Voting Behavior and the Electoral Context of Government Formation." Electoral Studies 24(2): 245-64.

Golder, Matt. 2005. "Democratic Electoral Systems Around the World, 1946-2000." Electoral Studies 24(1): 103-21.

Golder, Sona N. 2010. "Bargaining Delays in the Government Formation Process." Comparative Political Studies 43(1): 3-32.

Hensher, David A., and William H. Greene. 2003. "The Mixed Logit Model: The State of Practice." Transportation 30(2): 133-76.

Irwin, Galen A. 1995. "The Dutch Parliamentary Election of 1994." Electoral Studies 14(1): 72-77.

Isaksson, Guy-Erik. 2005. "From Election to Government: Principal Rules and Deviant Cases." Government and Opposition 40(3): 329-57.

Kang, Shin-Goo. 2009. "The Influence of Presidential Heads of State on Government Formation in European Democracies." European Journal of Political Research 48(4): 543-72.

Klingemann, Hans-Dieter, Andrea Volkens, Judith Bara, Ian Budge, and Michael McDonald, eds. 2006. Mapping Policy Preferences II. New York: Oxford University Press.

Kristinsson, Gunnar Helgi. 1999. "Iceland." In SemiPresidentialism in Europe, ed. Robert Elgie. New York: Oxford University Press, 86-103.

Laver, Michael, and Norman Schofield. 1990. Multiparty Government. New York: Oxford University Press.

Lupia, Arthur, and Kaare Strøm. 1995. “Coalition Termination and the Strategic Timing of Legislative Elections." American Political Science Review 89(3): 648-65.

Martin, Lanny W., and Randolph T. Stevenson. 2010. "Incumbency, Context, and Government Formation in Multiparty Parliamentary Democracies." American Political Science Review 104(3): 503-18.

Mattila, Mikko, and Tapio Raunio. 2004. "Does Winning Pay? Electoral Success and Government Formation in 15 West European Countries." European Journal of Political Research 43(2): 263-85.

McFadden, Daniel. 1974. "Conditional Logit Analysis of Qualitative Choice Behavior." In Frontiers in Econometrics, ed. P. Zarembka. New York: Academic Press, 105-42.

McFadden, Daniel, and Kenneth Train. 2000. "Mixed MNL Models for Discrete Response." Applied Econometrics 15(5): 447-70.

Müller, Wolfgang C., and Kaare Strøm, eds. 2000. Coalition Governments in Western Europe. Oxford: Oxford University Press.

Protsyk, Oleh. 2005. "Prime Ministers' Identity in SemiPresidential Regimes.” European Journal of Political Research 44(5): 721-48.

Ragin, Charles C. 1987. The Comparative Method: Moving Beyond Qualitative and Quantitative Strategies. Berkeley: University of California Press.

Schleiter, Petra, and Edward Morgan-Jones. 2009a. "Constitutional Power and Competing Risks." American Political Science Review 103(3): 496-512.

Schleiter, Petra, and Edward Morgan-Jones. 2009b. "Party Control over European Cabinets?" European Journal of Political Research 48(5): 665-93.

Snyder, James M., Michael M. Ting, and Stephen Ansolabehere. 2005. "Legislative Bargaining under Weighted Voting." American Economic Review 95(4): 981-1004.

Strøm, Kaare. 2000. "Delegation and Accountability in Parliamentary Democracies." European Journal of Political Research 37(3): 261-89.

Strøm, Kaare, Ian Budge, and Michael J. Laver. 1994. "Constraints on Cabinet Formation in Parliamentary Democracies." American Journal of Political Science 38(2): 30335.

Strøm, Kaare, Wolfgang C. Müller, and Torbjörn Bergman, eds. 2008. Cabinets and Coalition Bargaining: The Democratic Life Cycle in Western Europe. Oxford: Oxford University Press.

Tavits, Margit. 2009. Presidents with Prime Ministers: Do Direct Elections Matter? New York: Oxford University Press.

Timmermans, Arco, and Rudy B. Andeweg. 2000. "The Netherlands." In Coalition Governments in Western Europe, ed. Wolfgang C. Müller and Kaare Strøm. Oxford: Oxford University Press, 356-98.

Train, Kenneth. 1998. "Recreation Demand Models with Taste Differences over People." Land Economics 74(2): 230-39.

Warwick, Paul V. 1996. "Coalition Government Membership in West European Parliamentary Democracies.” British Journal of Political Science 26(4): 471-99.

Warwick, Paul V., and James N. Druckman. 2006. "The Portfolio Allocation Paradox." European Journal of Political Research 45(4): 635-65. 
Western, Bruce. 1998. "Causal Heterogeneity in Comparative Research." American Journal of Political Science 42(4): 1233-59.

\section{Supporting Information}

Additional Supporting Information may be found in the online version of this article:

Online Appendix A: Different Distributions for the Random Coefficients
Online Appendix B: All Governments

Online Appendix C: More Substantive Results from the Mixed Logit Model

Online Appendix D: Comparing Mixed Logit and Conditional Logit Results

Please note: Wiley-Blackwell is not responsible for the content or functionality of any supporting materials supplied by the authors. Any queries (other than missing material) should be directed to the corresponding author for the article. 